
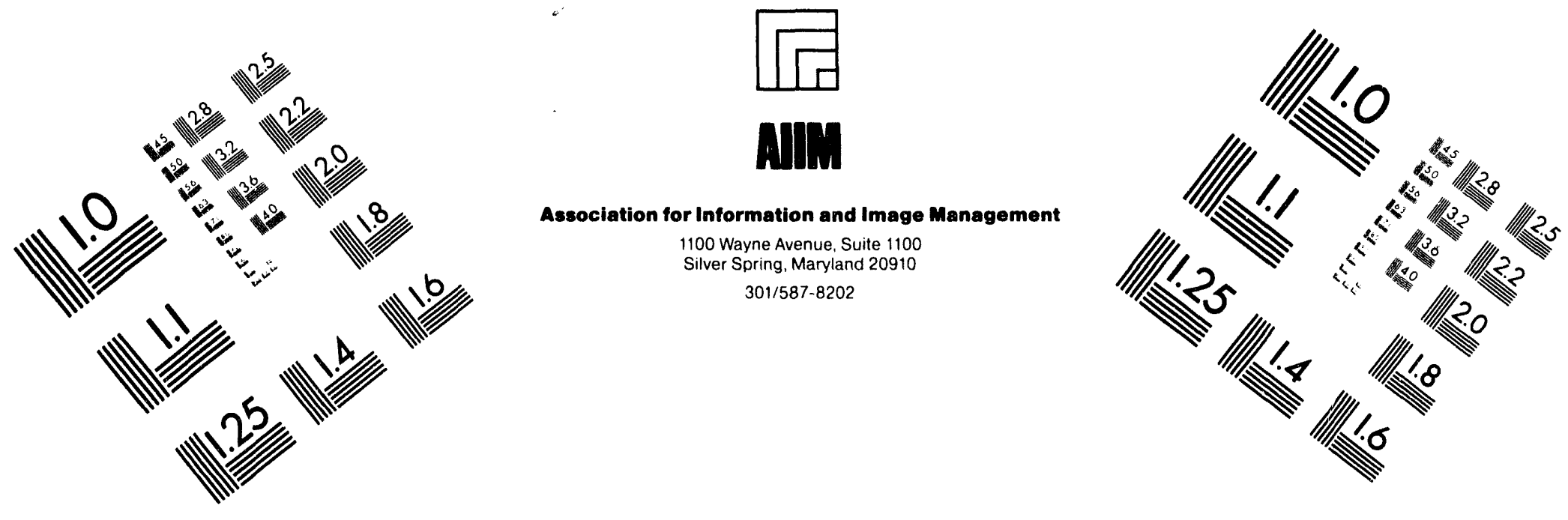

\title{
Centimeter
}

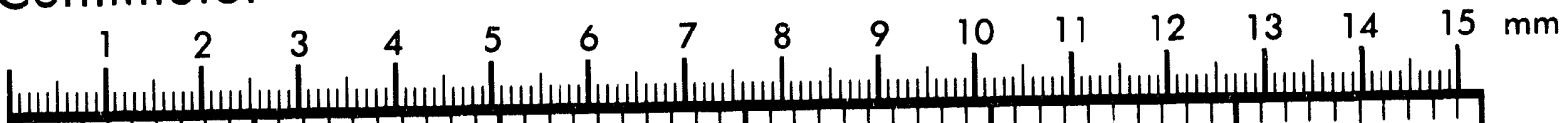
1 Inches

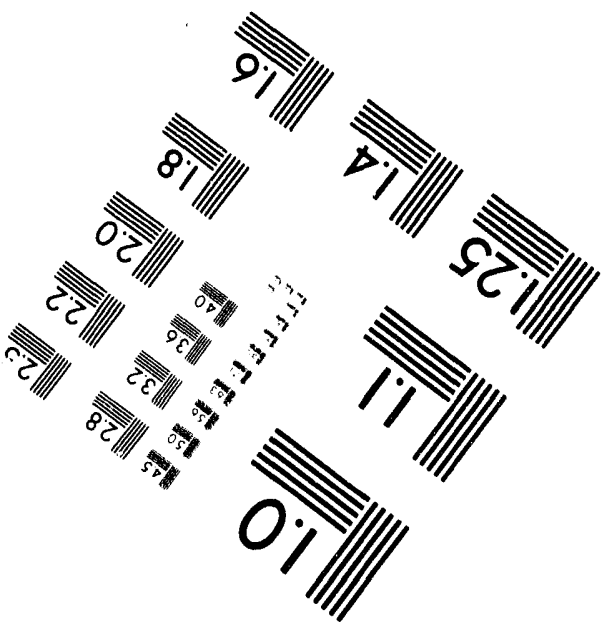

MANUFACTURED TO AIIM STANDARDS

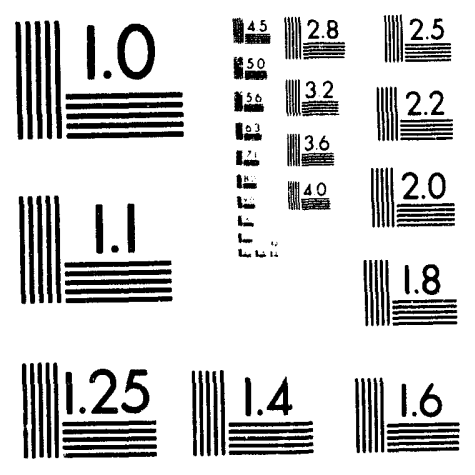

BY APPLIED IMAGE. INC.

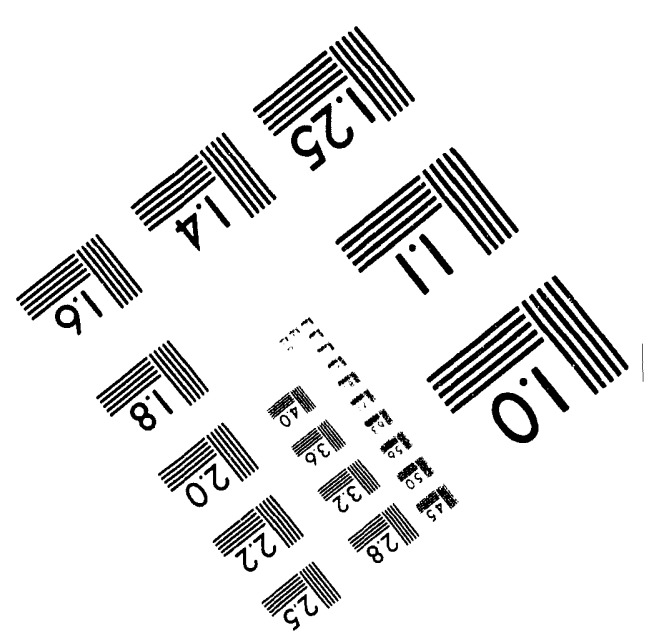



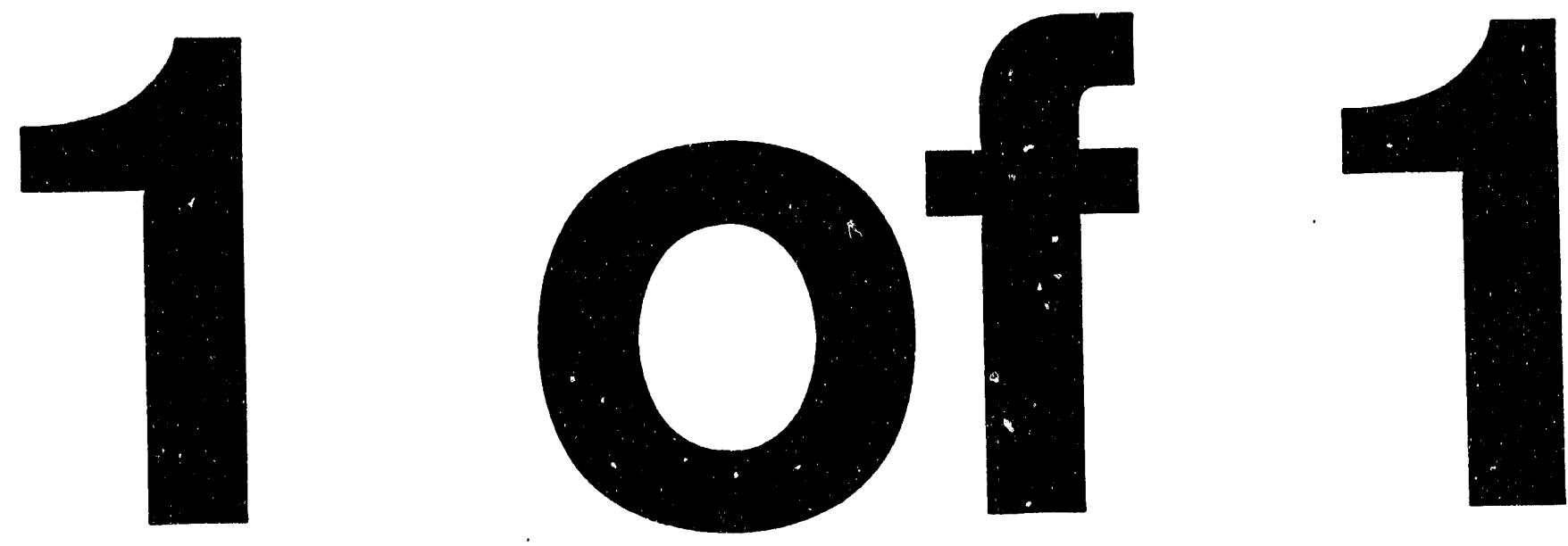


\section{ITER DESIGN: PHYSICS BASIS FOR SIZE, CONFINEMENT CAPABILITY POWER LEVELS AND BURN CONTROL}

Nermin A. Uckan

J. Hogan, W. Houlberg, J. Galambos

Oak Ridge National Laboratory*

P.O. Box 2009 (MS-8072)

Oak Ridge, Tennessee 37831-8072

(615) 574-1354

\author{
L.J. Perkins, S. Haney \\ Lawrence Livermore National Laboratory \\ P.O. Box 808 (L-644) \\ Livermore, CA $94551-9900$
}

\author{
D. Post, ${ }^{\dagger}$ S. Kaye \\ Princeton Plasma Physics Laboratory \\ P.O. Box 451 \\ Princeton, NJ 08543 \\ 'Present add: ITER-JCT, San Diego, CA.
}

\section{ABSTRACT}

The ITER-EDA(93) design has been analyzed to evaluate the physics basis for: (i) size and design trade-off issues, (ii) confinement capability, (iii) power levels, and (iv) burn control.

\section{DISCUSSIONS AND RESULTS}

The objectives for International Thermonuclear Experimental Reactor (ITER) are set by the ITER agreements. ${ }^{1}$ The ITER-EDA $(93)^{2}$ design variant has been analyzed to evaluate (i) physics basis for size and design trade-off issues, (ii) confinement capability, (iii) power levels (including operational limits and $\mathrm{H}$-mode threshold power), and (iv) burn control. Results are reported in a briefing material for the U.S. ITER Home Team (1993) for the Third Meeting of the ITER Technical Advisory Committee (TAC). ${ }^{3}$ Brief highlights are as follows:

\section{Size and Design Trade-off Issues}

Major device/plasma parameters for ITER-EDA $(93)^{2}$ and $\mathrm{CDA}^{4}$ are given in Table 1.

\section{TABLE 1. MAJOR DEYICE PARAMETERS}

\begin{tabular}{|llllcc|}
\hline Parameter & & \multicolumn{3}{c|}{ EDA(93) } & $\mathrm{CDA}$ \\
\hline Device/Plasma major radius & $\mathrm{R}_{\mathrm{d}} / \mathrm{R}$ & $(\mathrm{m})$ & $7.9 / 8.2$ & $6.0 / 6.0$ \\
Plasma minor radius & $\mathrm{a}$ & $(\mathrm{m})$ & 3.0 & 2.15 \\
Elongation (ave. @95\%) & $\mathrm{K} 95$ & -- & 1.51 & 1.98 \\
Triangularity (ave.@95\%) & $\delta_{95}$ & -- & 0.24 & 0.38 \\
Plasma volume & $\mathrm{V}_{\mathrm{p}}$ & $\left(\mathrm{m}^{3}\right)$ & 2200 & 1100 \\
Plasma surface area & $\mathrm{S}_{\mathrm{p}}$ & $\left(\mathrm{m}^{2}\right)$ & 1300 & 850 \\
Plasma current & $\mathrm{I}$ & $(\mathrm{MA})$ & 25 & 22 \\
Safety factor (@95\% flux) & $\mathrm{q}_{\psi 95}$ & -- & 2.9 & 3 \\
Toroidal field on axis & $\mathrm{B}$ & $(\mathrm{T})$ & 5.9 & 4.85 \\
Maximum toroidal field & $\mathrm{B}_{\max }(\mathrm{T})$ & 13 & 11.2 \\
Total flux-volt seconds & $\Phi_{\text {tot }}(\mathrm{Vs})$ & 625 & 325 \\
Configuration & -- & -- & $\mathrm{SN}$ & $\mathrm{DN}$ \\
\hline
\end{tabular}

*Managed by Martin Marietta Energy Systems, Inc. under contract DE-AC05-840R21400 with the U.S. DOE.
From a radial build, the definition of $q_{\psi}$ and aspect ratio $A(=R / a)$, and the $1 / R$ fall-off of the field $(B \sim 1 / R)$, a simple equation for the size of a tokamak is (Fig. 1):5

$$
\begin{gathered}
\mathrm{R}=\mathrm{R}_{\text {coil }}+\mathrm{d}_{\mathrm{BS}}+\mathrm{a}, \quad \mathrm{BR}=\mathrm{B}_{\text {coil }} \mathrm{R}_{\text {coil }} \\
\mathrm{q}_{\psi 95}=\mathrm{q}_{\mathrm{c}} \times f(\mathrm{~A}, \mathrm{~K}, \delta)=\left(5 \mathrm{a}^{2} \mathrm{~B} / \mathrm{RI}\right) \times f(\mathrm{~A}, \mathrm{~K}, \delta) \\
f(\mathrm{~A}=1 / \varepsilon, \kappa, \delta)=\left\{\left[1+\mathrm{K}^{2}\left(1+2 \delta^{2}-1.2 \delta^{3}\right)\right] / 2\right\} \\
\times\left[(1.17-0.65 \varepsilon) /\left(1-\varepsilon^{2}\right)^{2}\right] \\
\Rightarrow \quad \mathrm{a}=\left[\mathrm{I} \mathrm{A}^{2} \mathrm{q}_{\mathrm{c}} / 5 \mathrm{~B}_{\text {coil }}+\mathrm{d}_{\mathrm{BS}}\right] /(\mathrm{A}-1)
\end{gathered}
$$

The size is specified by the plasma current (I), $A, q_{\psi}(95 \%)$, plasma shape $(K, \delta)$, and max field at the coil $\left(B_{\text {coil }}\right)$.

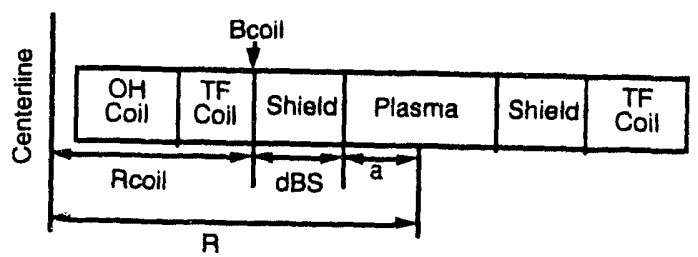

Fig. 1. Schematic radial build of a tokamak.

For most empirical energy confinement scalings, $\operatorname{Tn} \tau_{\mathrm{E}} \propto\left(\mathrm{IA} / \mathrm{R}^{0.3}\right)^{2.5 \pm 0.5}$, requiring $\mathrm{IA} \sim 50-60$ for $\mathrm{H}$ mode conditions for moderate $(10 / 1 \%) \mathrm{He} / \mathrm{Be}$ content. The requirement for $q_{\psi} \geq 3$ is needed to ensure MHD stability with a minimum disruption frequency and to maintain a favorable scaling of confinement with current. Other quantities are: $\mathrm{A} \sim 2.5-3.5, \mathrm{~d}_{\mathrm{BS}} \sim 1-1.2 \mathrm{~m}$, and $\mathrm{B}_{\text {coil }} \sim$ $11-13 \mathrm{~T}$. The CDA $\left(\mathrm{R} \sim 6 \mathrm{~m}, \mathrm{I} \sim 20 \mathrm{MA}, \mathrm{t}_{\text {burn }} \sim 200 \mathrm{~s}\right)$ and $\mathrm{EDA}(\mathrm{R} \sim 8 \mathrm{~m}, 25 \mathrm{MA}, \sim 1000 \mathrm{~s})$ designs follow from these constraints and the parameter choices for aspect ratio $(\sim 2.8)$ and elongation ( 2 for CDA and 1.5 for EDA).

The largest design drivers influencing the size increase from $\mathrm{CDA}$ to EDA are the confinement requirements at high $\mathrm{He}$ levels, longer pulse length, and lower $\kappa$. For a given mission and design goal, there is sufficient room for design optimization. Especially with the RLW model, confinement is not directly a function of plasma current and designs at signiticantly smaller sizes and lower currents can be found to satisfy the ignition requirement.

*Research sponsored by the Office of Fusion Energy, U.S. Department of Energy, under contract DE-AC05-
840R21400 with Martin Marietta Energy Systems, Inc.

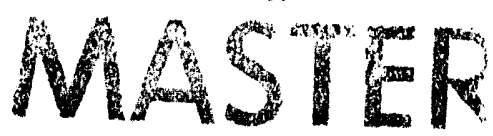




\section{Confinement Capability}

Ignition capability of the EDA (and CDA) is evaluated using 1-D and 0-D simulations under different confinement assumptions. Results from some of these simulations and confinement assessments are summarized in Table 2. In Table 2, ITER CDA-like physics guidelines ${ }^{6}$ [nominal profiles, $10-18 \% \mathrm{He}, 1-2 \% \mathrm{Be}$, and $\langle\mathrm{T}\rangle \sim 10 \mathrm{keV}]$ are used and ITER-EDA and CDA scenarios for ignition are shown. Calculations with empirical $\tau_{E}(\mathrm{~L}-, \mathrm{H}$-mode) scalings assume no power threshoid ( $\mathrm{L}-\mathrm{H}$ transition) for access to the improved confinement regime.

\section{TABLE 2. CONFINEMENT/IGNITION CAPABILITY} [Empirical scalings, 0-D model]

\begin{tabular}{|c|c|c|c|}
\hline \multicolumn{2}{|l|}{ Parameters } & $\mathrm{EDA}(93)$ & $\mathrm{CDA}$ \\
\hline I & (MA) & 25 & 22 \\
\hline $9 \psi$ & $\cdots$ & 2.9 & 3 \\
\hline Pfusion & $(\mathrm{MW})$ & 1500 & 1080 \\
\hline$L_{n}(n-w a l l ~ l o a d)$ & $\left(\mathrm{MW} / \mathrm{m}^{2}\right)$ & 0.93 & 1.0 \\
\hline$\langle\mathrm{T}\rangle_{\mathrm{n}}=\langle\mathrm{nT}\rangle \mid\langle\mathrm{n}\rangle$ & $(\mathrm{keV})$ & 10 & 10 \\
\hline$\left\langle\mathrm{n}_{\mathrm{e}}\right\rangle$ & $\left(10^{20} \mathrm{~m}^{-3}\right)$ & $1.0 \rightarrow 1.3$ & $1.2 \rightarrow 1.6$ \\
\hline $\mathrm{n}_{\mathrm{He}} / \mathrm{n}_{\mathrm{e}}$ & $(\%)$ & $10 \rightarrow 18$ & $10 \rightarrow 18$ \\
\hline $\mathrm{n}_{\mathrm{Be}} / \mathrm{n}_{\mathrm{e}}$ & $(\%)$ & $1 \rightarrow 1.7$ & $1 \rightarrow 1.7$ \\
\hline$Z_{\text {eff }}$ & -- & $1.3 \rightarrow 1.6$ & $1.3 \rightarrow 1.6$ \\
\hline Beta normal $\left[\beta_{N}=g\right]$ & $(\%)$ & $1.7 \rightarrow 1.9$ & $2.1 \rightarrow 2.4$ \\
\hline$\beta_{\mathrm{t}}($ total $)$ & $(\%)$ & $2.4 \rightarrow 2.7$ & $4.3 \rightarrow 5.0$ \\
\hline$\beta_{p}$ & -- & $0.48 \rightarrow 0.57$ & $0.64 \rightarrow 0.77$ \\
\hline$V_{\text {loop }}$ & (V) & $0.1 \rightarrow 0.13$ & $0.09 \rightarrow 1.1$ \\
\hline $\mathrm{TE}_{\mathrm{E}}$ & (s) $\quad$ & $4.1 \rightarrow 6.0$ & $3.4 \rightarrow 5.1$ \\
\hline \multicolumn{4}{|c|}{ Needed " $H$ " $=\tau_{E}$ (needed for ignition) $/ \tau_{E}$ (scaling): } \\
\hline \multicolumn{2}{|c|}{ ITER89P-L-mode } & $1.7 \rightarrow 2.1$ & $1.9 \rightarrow 2.5$ \\
\hline \multicolumn{2}{|c|}{ ITER890-L-mode } & $1.6 \rightarrow 2.1$ & $1.7 \rightarrow 2.3$ \\
\hline \multicolumn{2}{|c|}{ ITER90P-H (tot, elm-free) } & $0.5 \rightarrow 0.6$ & $0.7 \rightarrow 0.9$ \\
\hline \multicolumn{2}{|c|}{ ITER92P-H (th, elmy) } & $0.7 \rightarrow 0.8$ & $0.8 \rightarrow 0.9$ \\
\hline \multicolumn{2}{|l|}{ ITER93P-H (th, elmy) } & $0.6 \rightarrow 0.7$ & $0.7 \rightarrow 0.9$ \\
\hline
\end{tabular}

*Note: $\tau_{\mathrm{E}}=\mathrm{W}_{\mathrm{th}} /\left(\mathrm{P}_{\text {cond }}+\right.$ conv $)=\mathrm{W}_{\mathrm{th}} /\left(\mathrm{P}_{\alpha}+\mathrm{POH}_{\mathrm{OH}}-\mathrm{P}_{\mathrm{rad}}\right)$ Beta normal $=\mathrm{g} \cdot$ Troyon $=\beta_{\mathrm{t}}($ total $)(\%) /[\mathrm{I}(\mathrm{MA}) / \mathrm{a}(\mathrm{m}) \mathrm{B}(\mathrm{T})]$

The ignition capability of EDA plasma is somewhat higher than that of CDA by about $10-20 \%$ with most empirical scalings. Simulations with Rebut-Lalia-Watkins (RLW) $\chi\left(\nabla \mathrm{T}_{\mathrm{e}}\right)_{\text {crit }}$ model show that both the ITER-EDA and CDA scenarios operate in L-mode, however CDA ignition margin is much smaller.

At a higher $(\sim 20 \%)$ concentration of helium, the confinement capability is deteriorated (due to fuel particle dilution and an increase in bremsstrahlung losses) and the required confinement enhancement factor (over empirical Lmode scalings) is $\geq 2$, as shown in Table 2 .

Figure 2 illustrates the sensitivity of ITER ignition capability to $\mathrm{He}$ and $\mathrm{Be}$ content at a nominal fusion power of $1500 \mathrm{MW}$ (corresponding to a wall loading of $\sim 0.9$ $\mathrm{MW} / \mathrm{m}^{2}$ ). The sensitivity of ITER-EDA ignition capability to plasma current at $P_{\text {fus }}=1500 \mathrm{MW}$ (with $\mathrm{n}_{\mathrm{He}} / \mathrm{n}_{\mathrm{e}}=0-20 \%$ plus $\mathrm{n}_{\mathrm{Be}} / \mathrm{n}_{\mathrm{e}}=1$ ) is shown in Fig. 3 for ITER89 power-law (ITER89-P) scaling.

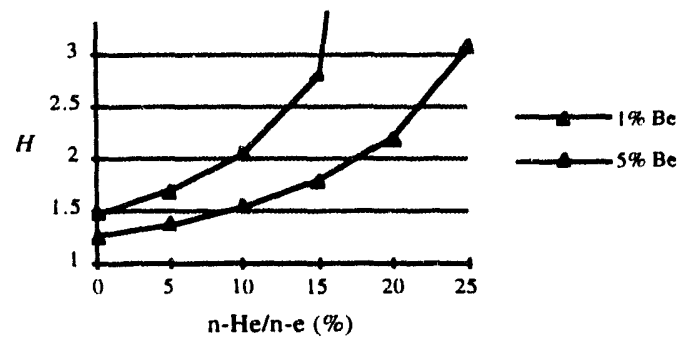

Fig. 2 Sensitivity of ITER EDA (1500 MW) performance to $\mathrm{He}$ (and $\mathrm{Be}$ ) content. Needed confinement improvement factor $\mathrm{H}$ vs helium concentration $\left[\mathrm{n}_{\mathrm{He}} / \mathrm{n}_{\mathrm{e}}(\%)\right]$, where $\mathrm{H}=\tau_{\mathrm{E}}$ (needed)/ $\tau_{\mathrm{E}}($ ITER89-P). Nominal profiles and $\langle\mathrm{T}\rangle \sim 10 \mathrm{keV}$ are used.

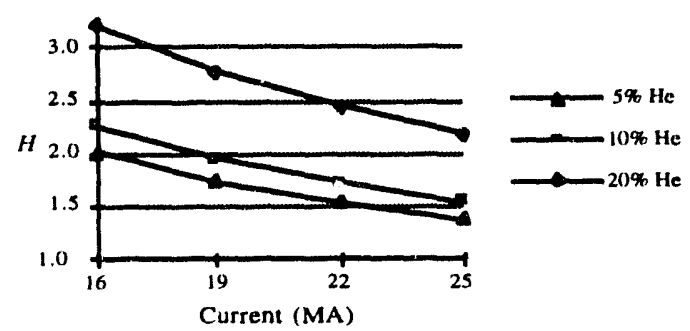

Fig. 3 ITER EDA ignition capability with ITER89-P Lmode scaling as a function of plasma current at $1500 \mathrm{MW}$ (for $\mathrm{n}_{\mathrm{He}} / \mathrm{n}_{\mathrm{e}}=0-20 \%, \mathrm{n}_{\mathrm{Be}} / \mathrm{n}_{\mathrm{e}}=1 \%$ ). $\mathrm{H}=\tau_{\mathrm{E}}$ (needed) $\tau_{\mathrm{E}}$ (scaling). Nominal profiles and $\langle\mathrm{T}\rangle \sim 10 \mathrm{keV}$ are used.

During the start-up/heating to ignition (before helium build-up), there is a large ignition window for $\mathrm{H}<2$ (Figs. 2 and 3). With power law scalings, during approach to ignition $(0-5 \% \mathrm{He}, 0-1 \% \mathrm{Be})$ the required $\mathrm{H}(89-\mathrm{P})<1.5$ for $I \geq 22$ MA. [With offset-linear scalings, not shown in Figs. 2 and $3 . \mathrm{H}(89-\mathrm{OL})<1.5$ for $\mathrm{I} \geq 19$.] During the burn, with favorable $\mathrm{H}$-mode conditions $(\mathrm{H}-2-2.5)$, ignition is predicted for plasma currents as low as $16 \mathrm{MA}$, even with high helium (10-20\%) content. With the RLW model, ignition in EDA plasmas was obtained for plasma currents as low as 10-12 MA (note that safety factor $q$ is higher in low current cases, and $\nabla q / q^{2}$ is important).

Figures 2 and 3 clearly indicate the need for effective helium exhaustimpurity control. The results from the experiments suggest that successful operation of ITER with adequate helium removal could be possible in either L-mode or in enhanced confinement regimes. ${ }^{7}$ 


\section{Fusion Power Levels}

Fusion power operational space ( $\min$ and $\max$ ) for sustained ignition is determined by a given confinement model, fuel dilution (He and impurity contents), and beta limit. A typical startup/ignition/burn scenario will evolve proceeding from an Ohmic plasma state to an ignition state (with the aid of auxiliary power) to a burn equilibrium state. Possible factors influencing the burn equilibrium at a given power level include: physics considerations (confinement, MHD stability/ beta limit, density limit. He/impurity accumulation, etc.), first wall/in-vessel/ divertor power handling capability, and the ability of PF coil system to maintain equilibrium control. The question of fusion power excursions and maximum power achievable is an important design and safety assessment issue, thus, it is necessary to design robust burn/operating point control schemes to minimize large power excursions beyond the design capability.

Fusion power operational space (minima and maximas) for sustained ignition as a function of $\mathrm{He}$ concentration (with $1 \%$ Be content) is shown in Fig. 4 for various confinement assumptions.

Predictions for minimum power are nearly the same for RLW L-mode and ITER89-OL (ITER89 offset-linear) scaling with $\mathrm{H} \sim 2$. At low $\mathrm{He}$ content (corresponding to conditions that are expected curing the start-up, $<5 \%$ ), $\mathrm{P}_{\text {fus-min }} \sim 300-500 \mathrm{MW}$ for RLW and for ITER-OL with $H>1.8$. With power law scalings (ITER89-P), the minimum fusion power to sustain ignition shows a strong threshold-like sensitivity to $\mathrm{He}$ concentration. With ITER89-P, the minimum power to sustain ignition at low He content ( $<5 \%$, during the start-up) is only a few hundred MW (for $\mathrm{H}>1.5$ ), primarily determined by the Ohmic (Neo-Alcator) scaling (not the ITER89-P). In Fig. $4, \tau_{E}=\min \left[\tau_{E}(\mathrm{OH}), \mathrm{H} \times \tau_{E}(\right.$ ITER89-P or ITER89-OL)]. Results from 1.5-D transport simulations ${ }^{8}$ with ITER89-P show $H \geq 1.3$ allow ohmic ignition at full design current. In these simulations, the fusion power at ignition is $\sim 300$ MW in calculations that assume no power threshold (L-H transition) for access to the improved confinement regime.

Fusion power operational space may be limited by the effects of the MHD beta limit, either though the confinement degrading effect of a "soft" beta limit, or by the onset of a disruption at a "hard" beta limit. Also important is the plasma density limit. An initial survey of $\mathrm{g}-l_{\mathrm{i}}$ requirements for stable operation of the EDA design showed that operation with $q_{95}<3$ and low triangularity would impose serious limitations on performance [ $\mathrm{g}_{\text {Troyon }}$ $<2.2$ for the EDA $l_{i}$ operating range]. If the typical MHD constraint $q(0)>1$ is relaxed by ignoring modes that are concentrated in the core (sawtooth) region, an increase in gTroyon could be realized for $0.6<l_{\mathrm{i}}<1.0$, if strong sawtoothing operation is deemed acceptable. The effect of beta-limit on achievable fusion power $\left(\mathrm{P}_{\text {fus-max }}\right)$ is shown in Fig. 4. For high He levels of $\sim 20 \%$, in EDA the fusion power is limited to $P_{\text {fus-max }} \leq 2500 \mathrm{MW}$ for $\mathrm{g} \leq 2.5$
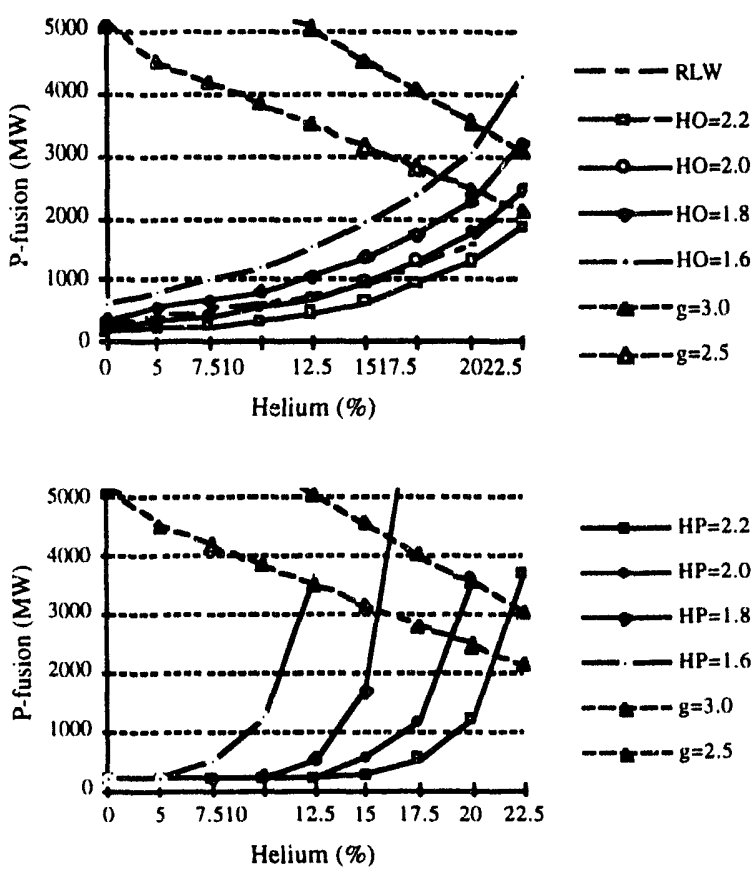

Fig. 4. Fusion power operational space ( $\min$ and $\max$ ) for sustained ignition as determined by confinement model, $\mathrm{He}(\mathrm{Be})$ content, and $\beta$ limit. Confinement model: ITER89-OL (top) and ITER89-P (bottom) scalings with $H=1.6-2.2$. Normalized beta with $\mathrm{g}=2.5-3$. $1 \% \mathrm{Be}$ content. Also shown is $\mathrm{min}$. fusion powers (for ignition) as predicted by RLW model. Operational domain is above the minpower needed for ignition (curves labeled by HP, $\mathrm{HO}$, and RLW) and below the max-power determined by the beta limit ( $\mathrm{g}=2.5-3$ curves).

Results reported in Fig. 4 with empirical scalings assume no pow " threshold (L-H transition) for access to the improved continement regime. An accurate estimate of $\mathrm{H}$-mode threshold power, $\mathrm{P}_{\mathrm{thr}}$, is necessary to determine the minimum auxiliary power requirements needed to reach ignition in ITER. From the available scalings, ${ }^{9}$

$$
\begin{aligned}
& \mathrm{P}_{\mathrm{thr}} / \mathrm{S}\left(\mathrm{MW} / \mathrm{m}^{2}\right) \geq(0.04-0.07) \times \mathrm{B}(\mathrm{T}) \mathrm{n}_{\mathrm{e}}\left(/ 10^{20} \mathrm{~m}^{-3}\right) \\
& \Rightarrow \mathrm{P}_{\mathrm{thr}}(\mathrm{MW}) \sim(300-500) \times \mathrm{n}_{\mathrm{e} 20} \text { in ITER-EDA. }
\end{aligned}
$$

If $P_{\mathrm{thr}}$ is large, under empirically based scalings (ITER89. $\mathrm{P}$, etc.), the $\mathrm{H}$-mode conditions may not be accessed early during the start-up/heating phase to ignition and large amounts of auxiliary power $\left(P_{\text {aux }}\right)$ are required under unfavorable L-mode conditions until net heating power, 
$\mathrm{P}($ alpha+OH+auxiliary-radiation), reaches the level of threshold power, $P_{t h r}$. During the start-up, at low densities $\left(n_{e} \sim 0.3-0.5 \times 10^{20} \mathrm{~m}^{-3}\right)$, the confinement (and, the plasma conditions) may well be determined by the Ohmic (Neo-Alcator) scaling, and it may be possible to achieve Ohmic ignition (aided by peaked density profiles and low He content) before the application of auxiliary heating, as seen in WHIST simulations. ${ }^{8}$ Under such scenarios, the optimal path in going from low density Ohmic ignition (at $\mathrm{P}_{\text {fus }} \sim 300 \mathrm{MW}$ ) to sustained ignition at high densities needs to be inapped out to determine the minimum auxiliary power requirements. Note that the ramifications are serious if the threshold power is well above 150-200 MW due to $P_{\text {aux }}$ required to access it.

\section{Burn control}

Because it is an important design and safety issue, it is necessary to design and develop robust burn/operating point control schemes to minimize large power excursions beyond the design capability.

In many simuiations (as in Ref. 2), the fusion power levels are controlled through the DT fueling rate and operation along the high temperature branch of the ignition curve. The proposed control scheme for EDA in Ref. 2 utilizes a feedback algorithm to adjust the rate of fuel injection as a function of the measured fusion rate. Although operation along the stable side of the ignition curve reduces the need for and complexity of "active" burn control, there are potential excursions whose magnitudes and effects have not yet been assessed.

One example of the type of assessment needed is in the area of density excursions. Perturbation of the balance between the plasma and plasma facing components leads to many instances of uncontrolled density excursions in present machines. Either abrupt changes in the plasma transport properties (e.g., L-H transitions) or recycling (e.g., enhanced desorption induced by higher energy charge exchange ions as auxiliary heating is increased) can often double the plasma density with no change in active fueling. Present divertor experiments indicate that continuous active pumping and fueling may reduce the magnitude of such excursions in ITER. The effects of wall-released fuel may also be ameliorated by enhanced pumping as density increases, and enhanced radiation from wall-generated impurities. Density excursions may also be coupled with plasma position control or thermal excursions. The extent of the excursions is in part governed by the fuel inventory in the plasma facing components, the sensitivity of this inventory to choice of material and the rate of release as a function of temperature.
In general, it is necessary to develop coupled engineering/physics scenarios and specifications for (i) operating point definition and control, (ii) burn stability contro', and (iii) off-normal transient control to be able to define specifications for minimum diagnostic, control, and shutdown systems. Operating point definition and control involves mapping of operating space to determine the choice of plasma conditions $\left(n, T, n_{H e} / n_{e}, n_{z} / n_{e}\right.$, etc.) and adjustable machine parameters (I, B, etc.) to yield desired levels of equilibrium fusion power within relevant physics and engineering constraint boundaries (confinement, beta, heat flux, etc.). Characteristic time scales here are $\sim$ minutes. Burn stability control involves the specification of methods for the detection and feedback. stabilization of temperature-driven and dersity-driven reactivity instabilities, both positive and negaiive. Characteristic time scales here are seconds to tens of seconds and real time control methods are required as the burn progresses. Finally, off-normal transient control involves the specification of control schemes to rapidly reduce the fusion power to zero when normal burn stability control fails and the plasma become super-ignited, or when the plasma operating stably at the desired equilibrium point but the external accident event (LOCA/LOFA in a torus component) necessitates a rapid reduction in fusion power on a time scale much shorter than a conventional shutdown period. Time scales involved here are $\sim 1-10 \mathrm{~s}$.

\section{REFERENCES}

1. "Establishment of ITER: Relevant Documents," ITER-CDA Doc. Series, No. 1, IAEA, Vienna (1988); "ITER EDA Agreement and Protocol I," ITER-EDA Doc. Series No. 1, IAEA, Vienna (1992); "ITER-EDA Agreement and Protocol II, " IAEA (1994).

2. "ITER-EDA Design Option Developments," presented by the ITER Director, ITER TAC-3 Report (1993).

3. N. A. Uckan et al., "Plasma Performance: physics basis for size, confinement capability, operational limits, power levels," U.S. TAC-3 Briefing Report, ITER/US/93/PH-17 (1993).

4. "ITER Conceptual Design Report," ITER CDA Doc. Series, No. 18, IAEA, Vienna (1991).

5. D. Post, N.A. Uckan, "Criteria and Design Trade-off Issues for ITER," Fusion Technol. 21, 1427 (1992)

6. N. A. Uckan, "ITER Physics Design Guidelines," ITER CDA Doc. Series, No. 10, IAEA, Vienna (1990); also ITER-TN-PH-0-5 (1990).

7. M. Wade et al., "Dependence of helium transport on plasma current and elm frequency in $\mathrm{H}$-mode discharges in DIII-D, " Proc. EPS Conf. Cont. Fusion and Plasma Phys., Vol. 17C, Part I, p.63 (1993).

8. W. A. Houlberg, 1-1/2-D WHIST simulations with $\chi$ (ITER89-P) (1993); also paper in these proceedings.

9. F. Ryter and H-mode Database Working Group, "An examination of the ITER H-mode power threshold database." Proc. EPS Conf Controlled Fusion and Plasma Phys., Vol. 17C, Part I, p.15 (1993). 


\section{DISCLAIMER}

This report was prepared as an account of work sponsored by an agency of the United States Government. Neither the United States Government nor any agency thereof, nor any of their employees, makes any warranty, express or implied, or assumes any legal liability or responsibility for the accuracy, completeness, or usefulness of any information, apparatus, product, or process disclosed, or represents that its use would not infringe privately owned rights. Reference herein to any specific commercial product, process, or service by trade name, trademark, manufacturer, or otherwise does not necessarily constitute or imply its endorsement, recommendation, or favoring by the United States Government or any agency thereof. The views and opinions of authors expressed herein do not necessarily state or reflect those of the United States Government or any agency thereof. 

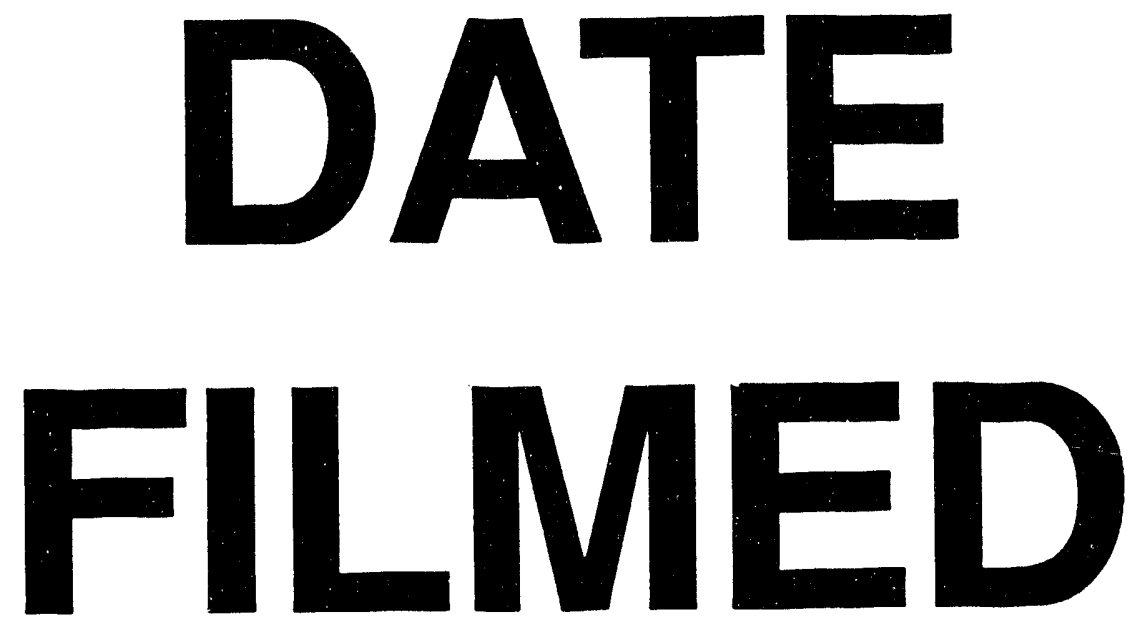

$10 / / 3 / 94$
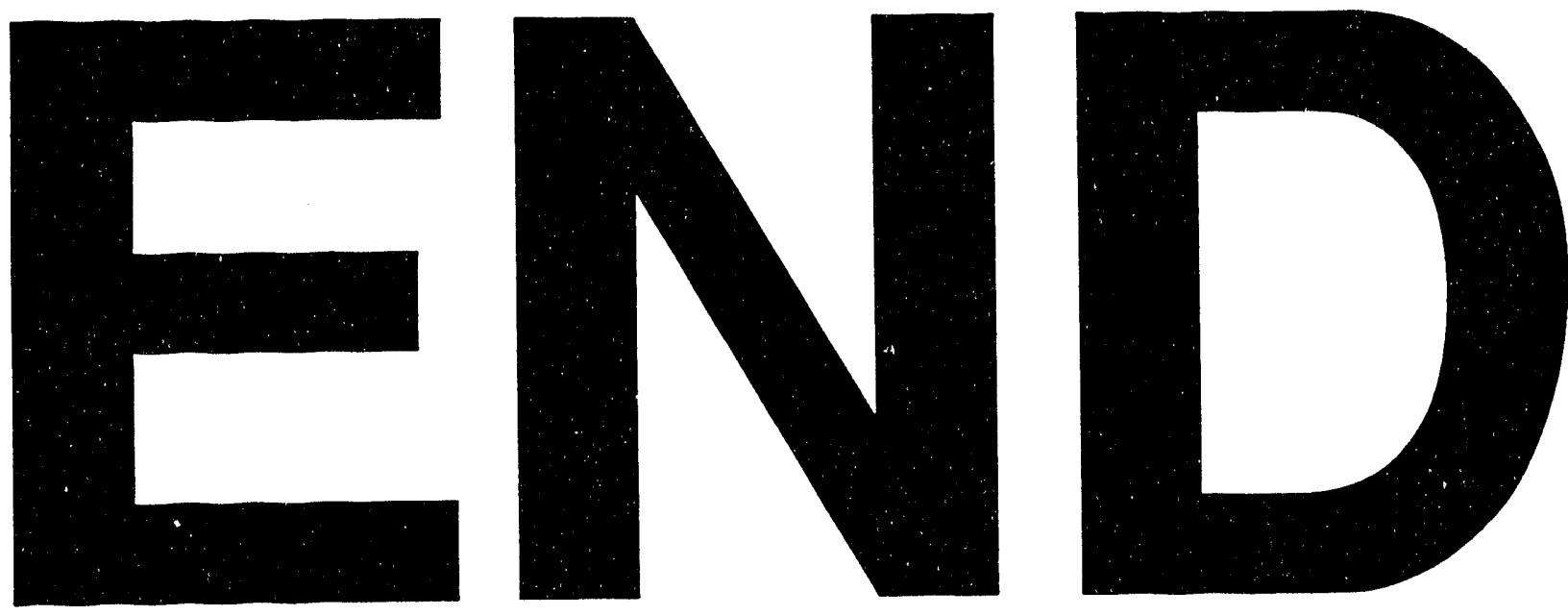
